\title{
Investigating the Influence that Service in a Pro Bono Clinic has on a First Full-Time Clinical Education Experience from the Perspective of Students and their Clinical Instructors
}

\author{
Ellen Erdman \\ Widener University, eaerdman@widener.edu \\ Jill D. Black \\ Widener University, jdblack@widener.edu \\ Sandra Campbell \\ Widener University, slcampbell@widener.edu \\ Tim Golder \\ Widener University, tmgolder@widener.edu \\ Stephen Grazioli \\ Widener University, sjgrazioli@widener.edu \\ See next page for additional authors \\ Follow this and additional works at: https://nsuworks.nova.edu/ijahsp \\ Part of the Physical Therapy Commons
}

\section{Recommended Citation}

Erdman E, Black JD, Campbell S, Golder T, Grazioli S, Palombaro KM. Investigating the Influence that Service in a Pro Bono Clinic has on a First Full-Time Clinical Education Experience from the Perspective of Students and their Clinical Instructors. The Internet Journal of Allied Health Sciences and Practice. 2020 Jan 01;18(4), Article 3.

This Manuscript is brought to you for free and open access by the College of Health Care Sciences at NSUWorks. It has been accepted for inclusion in Internet Journal of Allied Health Sciences and Practice by an authorized editor of NSUWorks. For more information, please contact nsuworks@nova.edu. 


\title{
Investigating the Influence that Service in a Pro Bono Clinic has on a First Full- Time Clinical Education Experience from the Perspective of Students and their Clinical Instructors
}

\begin{abstract}
Purpose: Academic physical therapy programs strive to foster student readiness for full-time clinical education experiences in a variety of ways. This research looks at one program who has students participate in a student-run pro bono clinic for at least 60 hours prior to the first full-time clinic experience. The purpose of the study is to explore the influence that participation in this pro bono clinic has on a first full-time clinical education experience from the perspective of both the student and the clinical instructor $(\mathrm{Cl})$. Methods: Qualitative methodology was employed to gain the perspectives of 29 students and their respective Cls. Data collection included student journals and focus groups, and $\mathrm{Cl}$ Likert-scale rankings and open-ended questions upon midterm calls. Data points were triangulated through iterative data analysis. Results: Cls rated students high in the eight categories that were triangulated to student data. The themes that were strongest among both students and Cis included comfort with client interaction, interaction with Cls, and cultural competency. Additional themes included documentation, interprofessional interaction, examination, clinical reasoning and intervention. An overarching theme was that students were well-prepared and functioning at high levels of competency for a first full-time clinical experience. Conclusions: Participation in a student-run pro bono clinic helps to facilitate student readiness for a first full-time clinical education experience according to both student perceptions and $\mathrm{Cl}$ ratings.
\end{abstract}

\section{Author Bio(s)}

Ellen Erdman, PT, DPT is a Clinical Associate Professor and the Director of Clinical Education at Widener University

Jill Black, PT, DPT, EdD is an Associate Professor and Pro Bono Services Coordinator at Widener University. She also serves as the Program Director and Associate Dean.

Sandra Campbell, PT, PhD is a Clinical Associate Professor and the Director of Clinical Education at Widener University.

Stephen Grazioli, DPT was the Marketing Student Leader for the Chester Community Clinic while a student in the DPT program at Widener University

Timothy Golder, DPT was the Clinic Coordinator for the Chester Community Clinic while a student in the DPT program at Widener University

Kerstin Palombaro, PT, Ph.D., CAPS is an Associate Professor and Community Engagement Coordinator at Widener University.

Authors

Ellen Erdman, Jill D. Black, Sandra Campbell, Tim Golder, Stephen Grazioli, and Kerstin M. Palombaro 


\title{
IIIAHSP \\ The Internet Journal of Allied Health Sciences and Practice
}

Dedicated to allied health professional practice and education

Vol. 18 No. 4 ISSN 1540-580X

\section{Investigating the Influence that Service in a Pro Bono Clinic has on a First Full- Time Clinical Education Experience from the Perspective of Students and their Clinical Instructors}

\author{
Ellen Erdman, PT, DPT \\ Jill D. Black, PT, DPT, EdD \\ Sandra Campbell, PT, Ph.D., MBA \\ Tim Golder, PT, DPT \\ Stephen Graziolo, PT, DPT \\ Kerstin M. Palombaro, PT, Ph.D., CAPS \\ Widener University \\ United States
}

\begin{abstract}
Purpose: Academic physical therapy programs strive to foster student readiness for full-time clinical education experiences in a variety of ways. This research looks at one program who has students participate in a student-run pro bono clinic for at least 60 hours prior to the first full-time clinic experience. The purpose of the study is to explore the influence that participation in this pro bono clinic has on a first full-time clinical education experience from the perspective of both the student and the clinical instructor (CI). Methods: Qualitative methodology was employed to gain the perspectives of 29 students and their respective Cls. Data collection included student journals and focus groups, and $\mathrm{Cl}$ Likert-scale rankings and open-ended questions upon midterm calls. Data points were triangulated through iterative data analysis. Results: Cls rated students high in the eight categories that were triangulated to student data. The themes that were strongest among both students and Cis included comfort with client interaction, interaction with $\mathrm{Cls}$, and cultural competency. Additional themes included documentation, interprofessional interaction, examination, clinical reasoning, and intervention. An overarching theme was that students were well-prepared and functioning at high levels of competency for a first full-time clinical experience. Conclusions: Participation in a student-run pro bono clinic helps to facilitate student readiness for a first full-time clinical education experience according to both student perceptions and $\mathrm{Cl}$ ratings.
\end{abstract}

Keywords: pro bono, clinical education, physical therapy

\section{CONFLICT OF INTEREST}

None of the authors have a financial conflict of interest to declare. 


\section{INTRODUCTION AND REVIEW OF THE LITERATURE}

The Commission for Accreditation in Physical Therapy Education (CAPTE) has standards that every academic program must achieve. These CAPTE standards inform both the didactic and clinical education curriculum. Specifically, CAPTE criteria 4N states that "Collective core faculty are responsible for assuring that students are safe and ready to progress to clinical education." (1. 15) In 2007, Jette et al identified seven themes essential for full-time clinical preparedness: knowledge, clinical skills, safety, clinical decisions, self-directed learning, interpersonal communication, and professional demeanor. ${ }^{2}$ In 2017, the American Council of Academic Physical Therapy (ACAPT) created a task force to investigate physical therapy student readiness for full-time clinical education with a Delphi study yielding consensus around minimal competencies for students entering their first full-time clinical education experience. The most important theme was related to basic knowledge utilized in clinical application and decision making. Additional themes emerged relating to self-assessment, communication, and professional behavior. ${ }^{3}$ Strategies that enable students to master clinical skills, solve problems, develop clinical decision-making skills, and become reflective practitioners are important early in health professional training. ${ }^{4}$

The literature shows a variety of curricular designs and learning experiences that programs have used to foster clinic readiness. Strategies include simulation with standardized patients both to prepare students for clinical education and screen for clinic readiness ${ }^{5,6}$ Integrated clinical experiences at university onsite clinics have been shown to improve application and integration of course content and have led to higher ratings in safety in the first full-time clinical experience. ${ }^{7,8}$ Service-learning experiences have also been shown to facilitate clinic readiness by offering opportunities to make application of didactic coursework. 9-11 $^{-11}$ The literature is growing in its description of student-run pro bono clinics as a strategy to enhance students' perceptions of clinic readiness. ${ }^{12-15}$ Participation in pro bono clinics has shown to develop student confidence, professional core values, and cultural competency. ${ }^{12-13,15-20}$ These studies have been based on student reflections and self-assessment. In 2019, Giles et al found students that participated more often in a pro bono clinic had higher rankings on the American Physical Therapy Association's Physical Therapist Clinical Performance Instrument (CPI) at midterm and final in items related to safety, professional behavior, cultural competency, and clinical reasoning as assessed by the Clinical Instructor $(\mathrm{Cl}) .{ }^{21}$ To date, this is the only article that considers how pro bono clinic service prepares students from the perspective of the $\mathrm{Cl}$.

The Chester Community Clinic is a student-run clinic treating the uninsured or underinsured community members of the Chester, PA community. Widener University's Institute for Physical Therapy Education students are scheduled to participate in the pro bono clinic a total of 60-70 hours where they treat patients with a variety of pathologies prior to their first full-time clinical experience. Students are supervised by licensed physical therapists who serve as mentors throughout the treatment process. ${ }^{22}$ This unique experience allows the students to transfer what they learn in the classroom to the evaluation and treatment of patients in the community. Porretta et al looked at the impact that participation in the pro bono clinic had on the first full-time clinical education experience from the student perspective but did not capture the perspective of the $\mathrm{Cl}^{15}$ The purpose of the study is to explore the influence that participation in a pro bono clinic has on a first full-time clinical education experience from the perspective of both the student and the $\mathrm{Cl}$.

\section{METHODOLOGY \\ Design}

The research design incorporated qualitative data collection methods from both student and $\mathrm{Cl}$ participants. Student participants kept journals and had the option to participate in one of four follow-up focus groups. Cls completed a midterm Likert-scale questionnaire administered by one of the two researchers who were also Directors of Clinical Education (DCE). Additionally, $\mathrm{Cl}$ midterm comments offered during the midterm interview helped triangulate the data. The research was approved by the Widener University Institutional Review Board.

Participants were pairs of students and $\mathrm{Cls}$. Both the student and the $\mathrm{Cl}$ needed to give informed consent in order to be eligible to participate as a pair. In accordance with clinical education policy, all Cls have at least 1 year of clinical experience and have completed formal training in assessment of student clinical performance. The students needed to be third-year students in the DPT program ready to participate in their first full-time, 10-week clinical experience. Student recruitment took place before Cls were recruited. Eligible students were told about potential study participation during a clinical education meeting prior to the start of the full-time clinical. Clinic readiness was based on successful advancement through the CAPTE-approved curriculum. Interested students signed informed consent to participate. Once the students gave informed consent, the DCEs worked with the Site Coordinators of Clinical Education and subsequently sought informed consent of the $\mathrm{Cl}$ assigned to the consenting student. 


\section{Data Collection}

Each student participant kept a journal throughout the first five weeks of their 10-week, full-time clinical experience. Students were instructed to note any influences that their experience in the pro bono clinic might be having on their full-time clinical practice experience. The journal guide prompts were developed from a previous study and are included in Appendix A. ${ }^{15}$ Two months after completion of their ten-week, full-time clinical experience, students were invited to participate in one of four focus groups facilitated by two researchers. The research team developed the focus group questions after reading through the student journals and noting questions for further clarification. The interview guide for the focus group is included in Appendix B. The focus groups were conducted on campus, recorded and transcribed verbatim.

The DCEs conducted the midterm interview with the consenting Cls at the same time as their scheduled midterm phone call or midterm visit. The DCEs posed the additional Likert-scale questions and open-ended questions at the end of their standard clinical education midterm interview. They asked the Cls to rate the student's performance during the first few weeks of the clinical experience as compared to their expectations for a DPT first full-time clinical experience. The CPI served as a conceptual framework for the questions and the modified tool used is included in Appendix C. ${ }^{23}$ Cls participating in the study spent an additional 15 minutes beyond the usual length of the midterm conversation. In the previous study, data collection had continued to the end of the clinical experience, blurring whether benefits were from the earlier pro bono experience or from the entire clinical experience. ${ }^{15}$ Data collection related to student journals and focus group responses and $\mathrm{Cl}$ interviews were purposefully collected at midterm to best capture the influence of the earlier pro bono clinic experience.

\section{Data Analysis}

Prior to data analysis, one of the researchers systematically de-identified the student journals and another researcher de-identified the $\mathrm{Cl}$ responses. There was no attempt to correlate $\mathrm{Cl}$ and student sources. De-identified $\mathrm{Cl}$ comments and rankings were analyzed for themes and congruency with student findings. $\mathrm{Cl}$ rankings were tallied and $\mathrm{Cl}$ comments were analyzed using content analysis principles. Student focus group transcripts identified participants by number. Student journals and focus group transcripts were analyzed in an iterative qualitative fashion by 5 of the 6 researchers and emergent themes were identified and discussed to produce consensus of themes. Data analysis examined frequency of each responses in addition to content. Those items with highest frequency within student journals and focus group transcripts as well as highest $\mathrm{Cl}$ Likert-scale ratings were identified as stronger themes and tiered accordingly. The findings from the previous research were used as a conceptual framework for comparison. ${ }^{15}$ The themes emergent from the student data were linked with the most relevant CPI skill area to allow for cross comparison of $\mathrm{Cl}$ and student data.

\section{Trustworthiness of Findings}

Trustworthiness and confirmability of findings were strengthened by the triangulation of multiple data points across both students and $\mathrm{Cl}$ participants. Presentation of verbatim quotes added validity and the researchers were diligent to ensure a variety of voice representation. As for reflexivity, two of the researchers were DCEs, two others were faculty members overseeing community engagement activities, and the final two researchers were students from the cohort of study. The two student researchers were not participants and did not have access to confidential student records at any time. The combined lenses of the researchers provided depth of insight and perspective in the data analysis.

\section{RESULTS}

Twenty-nine pairs of $\mathrm{Cls}$ and students participated in the study. Twenty-nine students completed journals and their respective twenty-nine Cls participated in the midterm interview and surveys. Twenty-eight students participated in one of four focus groups. Demographic information collected for the Cls included number of years in practice, number of years as a $\mathrm{Cl}$, and number of students supervised in their career. Most Cls reported over 6 years of clinical experience, with 2 years being the least years of experience as a licensed physical therapist. All but one $\mathrm{Cl}$ had supervised multiple full-time PT students. Eleven reported they had taken the basic APTA Credentialed Clinical Instructor course, and one had taken the Advanced Credentialed Clinical Instructor Course. Demographic information collected on Cls are present in Table 1. Demographic information collected on the participating students included gender, type of clinical site, geographic location of the site, and the student role in the Clinic (Student Board Member vs. Student Clinician) and is depicted in Table 2. 
TABLE 1. $\mathrm{Cl}$ Demographics $(\mathrm{n}=29)$

\begin{tabular}{|c|c|c|c|c|c|}
\hline Years in practice & 2 & $3-5$ & $6-10$ & $11-20$ & $20+$ \\
\hline & 2 & 5 & 9 & 8 & 5 \\
\hline \multirow{2}{*}{ Years as a $\mathrm{Cl}$} & $<1$ & $1-2$ & $3-5$ & $6-10$ & $11+$ \\
\hline & 1 & 3 & 11 & 2 & 12 \\
\hline \multirow{3}{*}{$\begin{array}{l}\text { Number of DPT } \\
\text { students supervised }\end{array}$} & & & & & \\
\hline & 1st & $2-5$ & $6-10$ & $11-20$ & $20+$ \\
\hline & 1 & 6 & 14 & 5 & 3 \\
\hline \multirow{2}{*}{$\begin{array}{l}\text { APTA CI Credentialing } \\
\text { Course }\end{array}$} & Beginner/Level & Advanced/Level & Neither & & \\
\hline & 10 & 1 & 18 & & \\
\hline \multirow[t]{2}{*}{ Practice Setting } & Outpatient & Acute Care & $\begin{array}{c}\text { Inpatient } \\
\text { Rehab }\end{array}$ & $\begin{array}{l}\text { International } \\
\text { Developed }\end{array}$ & $\begin{array}{c}\text { International } \\
\text { Developing }\end{array}$ \\
\hline & 17 & 6 & 2 & 2 & 2 \\
\hline
\end{tabular}

TABLE 2. Student Demographics $(n=29)$

\begin{tabular}{|l|l|l|l|}
\hline Participant \# & Gender & First Full-Time Clinic Setting & Role in Pro Bono Clinic \\
\hline 1 & Female & Acute & Student Board Member \\
\hline 2 & Male & Inpatient Rehab & Student Board Member \\
\hline 3 & Male & Outpatient & Student Board Member \\
\hline 4 & Male & Acute & Student Board Member \\
\hline 5 & Male & Outpatient & Student Clinician \\
\hline 6 & Female & Outpatient & Student Board Member \\
\hline 7 & Male & Acute & Student Clinician \\
\hline 8 & Female & Outpatient & Student Board Member \\
\hline 9 & Male & Acute & Student Clinician \\
\hline 10 & Male & Outpatient & Student Clinician \\
\hline 11 & Female & Outpatient & Student Clinician \\
\hline 12 & Female & Inpatient Rehab & Student Board Member \\
\hline 13 & Male & Outpatient & Student Clinician \\
\hline 14 & Female & Outpatient & Student Clinician \\
\hline 15 & Male & Outpatient & Student Clinician \\
\hline 16 & Female & Outpatient & Student Clinician \\
\hline 17 & Male & International & Student Clinician \\
\hline 18 & Male & Outpatient & Student Clinician \\
\hline 19 & Male & Outpatient & Student Board Member \\
\hline 20 & Female & Acute & Student Clinician \\
\hline 21 & Female & Outpatient & Student Clinician \\
\hline 22 & Male & Outpatient & Student Clinician \\
\hline 23 & Female & International - Developing & Student Board Member \\
\hline 34 & Male & International & Student Clinician \\
\hline 25 & Female & International - Developing & Student Board Member \\
\hline 26 & Male & Outpatient & Student Clinician \\
\hline 27 & Female & Acute & Student Clinician \\
\hline 28 & Female & Outpatient & Student Clinician \\
\hline 29 & Male & Outpatient & Student Clinician \\
\hline & & & \\
\hline
\end{tabular}


Results of the CI Likert scale ratings are in Table 3. A tally of the $\mathrm{Cl}$ ratings for "Above" and "Strongly Exceeds" expectations for student level of education indicating a strength in student performance was observed in the areas of Patient Communication, Cultural Competence, Documentation, and Professional Behaviors.

TABLE 3. Cl's Ranking of Student Performance in Comparison to their Expectations for a First Full-Time Clinical Experience

\begin{tabular}{|c|c|c|c|c|c|c|}
\hline CPI Skill area & $\begin{array}{c}\text { Below } \\
\text { expected } \\
\text { level }\end{array}$ & $\begin{array}{l}\text { Slightly } \\
\text { below } \\
\text { expected } \\
\text { level } \\
2\end{array}$ & $\begin{array}{c}\text { At } \\
\text { expected } \\
\text { level for } \\
\text { education } \\
3\end{array}$ & $\begin{array}{c}\text { Above } \\
\text { expected } \\
\text { level for } \\
\text { education } \\
4\end{array}$ & $\begin{array}{c}\text { Strongly } \\
\text { exceeds } \\
\text { expectations } \\
\text { for this level } \\
5\end{array}$ & $\begin{array}{c}\text { Total } 4+5 \\
\text { Ratings }\end{array}$ \\
\hline $\begin{array}{l}\text { Communication with the } \\
\text { patient }\end{array}$ & - & 2 & 3 & 17 & 8 & $25 / 29$ \\
\hline $\begin{array}{l}\text { Ability to accept and } \\
\text { utilize feedback }\end{array}$ & - & - & 5 & 15 & 10 & $25 / 29$ \\
\hline $\begin{array}{l}\text { Competency in Cultural } \\
\text { Encounters }\end{array}$ & - & - & 6 & 8 & 16 & $24 / 29$ \\
\hline Documentation & - & - & 12 & 16 & 2 & $18 / 29$ \\
\hline $\begin{array}{l}\text { Professional } \\
\text { communication }\end{array}$ & - & 1 & 13 & 8 & 8 & $16 / 29$ \\
\hline $\begin{array}{l}\text { Competency with } \\
\text { Examination }\end{array}$ & - & - & 14 & 14 & 2 & $16 / 29$ \\
\hline $\begin{array}{l}\text { Competency in Clinical } \\
\text { Reasoning }\end{array}$ & - & - & 15 & 14 & 1 & $15 / 29$ \\
\hline $\begin{array}{l}\text { Competency in } \\
\text { Interventions }\end{array}$ & - & - & 16 & 12 & 2 & $14 / 29$ \\
\hline
\end{tabular}

From the student data, a total of eight themes emerged at various levels of strength and included comfort with client interaction, comfort with $\mathrm{Cl}$ interaction, cultural competency, documentation, interprofessional communication, comfort with examination, clinical reasoning, and intervention. Strength was determined by the repetition of the theme across all student data points. Table 4 depicts a correlation of the $\mathrm{Cl}$ ratings with the student themes.

TABLE 4. CI Ratings in CPI Skill Areas and Aligned with Strength of Student Themes

\begin{tabular}{|l|l|l|l|}
\hline CPI Skill Area & $\begin{array}{l}\text { Cls rating at above } \\
\text { expected level }(\mathbf{4}+5)\end{array}$ & $\begin{array}{l}\text { Strength from Student } \\
\text { Perspective }\end{array}$ & Student Themes \\
\hline $\begin{array}{l}\text { Communication with the } \\
\text { patient }\end{array}$ & $25 / 29$ & Highest & Comfort with Client Interaction \\
\hline $\begin{array}{l}\text { Ability to accept and utilize } \\
\text { feedback }\end{array}$ & $25 / 29$ & High & Comfort with Cl Interaction \\
\hline $\begin{array}{l}\text { Competency in Cultural } \\
\text { Encounters }\end{array}$ & $24 / 29$ & High & Cultural Competency \\
\hline Documentation & $18 / 29$ & Medium & Documentation \\
\hline $\begin{array}{l}\text { Professional } \\
\text { communication }\end{array}$ & $16 / 29$ & Medium & Interprofessional Communication \\
\hline $\begin{array}{l}\text { Competency with } \\
\text { Examination }\end{array}$ & $16 / 29$ & Medium & Examination \\
\hline $\begin{array}{l}\text { Competency in Clinical } \\
\text { Reasoning }\end{array}$ & $15 / 29$ & Lowest & Clinical Reasoning \\
\hline $\begin{array}{l}\text { Competency in } \\
\text { Interventions }\end{array}$ & $14 / 29$ & Lowest & Intervention \\
\hline
\end{tabular}




\section{Comfort with Client Interaction}

The theme that was most representative across both the student and the $\mathrm{Cl}$ data and therefore earned ranking at the highest tier was comfort with client interaction which included rapport, trust, communication, and hands-on physical touch. In the area of communication with the patient, the CPI category that most relates to the student theme of "comfort with client interaction," $\mathrm{Cl}$ comments included "comfortable at bedside," "does not act like a student on a first clinical," and "can talk with patients at ease." Cls reported that students had established a basic comfort level to speak with strangers/clients and understanding the role of the physical therapist. Twenty-five of $30 \mathrm{Cls}$ rated the students' $\mathrm{CPI}$ skill area of "communication with the patient" above the expected level (rating of 4 or 5). The data from the Cls specifically corroborated student strength with client communication and with handson skills. Student quotes from focus groups supported this finding:

The communication and patient interaction definitely helped a lot. Having had that prior experience made me more comfortable going in and talking with patients right off the bat. (FOCUS GROUP 1)

I see other students and it seems they feel awkward touching and being hands on with a patient whereas having two years of experience with actually being hands-on with patients, real-life patients in our clinic, I never felt awkward once. (FOCUS GROUP 3)

\section{Comfort with $\mathrm{Cl}$ Interaction}

The second tier included two themes: comfort with $\mathrm{Cl}$ interaction and cultural competency. Cls comments in the corresponding CPI skill area of accepting and utilizing feedback included "accepts feedback well, aware of her needs and seeks assistance," "selfassesses and accepts feedback without being defensive," and "works with me $(\mathrm{Cl})$, asks questions, and seeks to understand why." Professional communication comments included, "takes the lead appropriately" and "does not need cues." Like the CPI skill area of "communication with the patient," 25 of $30 \mathrm{Cls}$ scored students above expected levels (rating of 4 or 5 ) in the skill area of "ability to accept and utilize feedback." Student journal entries demonstrated that students felt comfortable accepting feedback and communicating with their Cls.

I have learned how to communicate well with $\mathrm{my} \mathrm{Cl}$ and I was prepared for her to ask me questions because it is similar to having a supervisor at the pro bono clinic. (STUDENT 2 Journal)

When a supervisor or clinician approaches me with questions or concerns about a client, I am required to give them the pertinent information and my own assessment in a condensed version. This is a skill that I have had practice with while at the pro bono clinic and speaking with supervisors... (STUDENT 3 Journal)

Working in the pro bono clinic has made me value the importance of taking feedback and asking questions in the moment to the supervisors. (STUDENT 10 Journal)

\section{Cultural Competency}

In the area of cultural competency, Cls consistently gave the students the high rankings. Comments in this area included "adapts well, treats all patients the same," "goes out of way to find resources," and "uses interpreter well." In the CPI skill area of competency in cultural encounters, 24 of the $30 \mathrm{Cls}$ rated their students above expected level (rating of 4 or 5 ). Student focus group transcripts consistently reported experiences and stories where the students had to recognize cultural barriers and work to negotiate effectively through them.

It definitely helped with cultural competency, especially because I worked with a client in the pro bono clinic who needed an interpreter. When this need arose in my clinical experience, I didn't even blink an eye. The other student I was with had no idea what to do with an interpreter. The clinic helped me not to be freaked out like other students I saw. (FOCUS GROUP 2)

I think the main thing the clinic prepared me for was the cultural aspect of socioeconomic differences. The area the hospital was in was a lower socioeconomic area, and the problems the patients were having socially, like alcoholism, issues at home, limited home environment setup options, things our patients in the [pro bono] clinic also experienced as barriers. Educating patients on options and talking and being comfortable with those barriers was something I got out of the clinic. (FOCUS GROUP 2) 


\section{Documentation}

The medium tier of themes included documentation, interprofessional interaction and clinical examination. In the area of documentation, Cls report "thorough, able to highlight key issues," "content is good, working on conciseness," "picked up EMR quickly," "knows what needs to be in the note to justify services," "comprehensive, minimal cues needed," and "wordy, but content is there".

In the CPI skill area of documentation, 18 of the $30 \mathrm{Cls}$ rated their students as above expected level (rating of 4 or 5 ). Students consistently reported that documentation was a strength due to their prior documenting experience in the pro bono clinic.

The pro bono clinic gave me the confidence and practice to hone my note writing skills. $\mathrm{My} \mathrm{Cl}$ was very impressed with my daily notes and even said that they "looked like a seasoned veteran's note." (STUDENT 7 Journal)

I do believe writing treatment notes at the pro bono clinic has given me confidence and ability with this skill. Since I already had a strong foundation in this skill, I have been able to get more efficient at this skill while out in clinical. (STUDENT 10 Journal)

\section{Interprofessional Interaction}

Interprofessional Interaction falls under the category of Professional Communication on the CPI. In the CPI skill area of professional communication, 16 of the $30 \mathrm{Cls}$ rated their students as above expected level (rating of 4 or 5). Interprofessional interaction is reflected in the following student quotes:

The clinic definitely helped with interprofessional communication. I felt very comfortable just going up to the OTs and talking to them without having to have the $\mathrm{Cl}$ with me. I felt like I knew what OT's were doing too because of the interaction in the (pro bono) clinic. (FOCUS GROUP 3)

I greatly appreciated how we brought OT and clinical psychology students into the pro bono clinic. In my clinical placement, I was always with an OT, so having an understanding of what they did ahead of time was helpful. It also helped me feel more confident communicating with nurses and physicians. (FOCUS GROUP 1)

\section{Examination}

$\mathrm{Cl}$ comments and ratings identified strength in competency in examination, interventions, and clinical reasoning, with comments including "solid, needs to work on flow" and "hands on skills are better than expected." Rankings on the Likert scale were at or above the expected level for this point in the curriculum. In the area of competency in examination, 16 of the $30 \mathrm{Cls}$ rated their students above expected level. The students expressed that their time in the pro bono clinic helped them feel more comfortable and confident with clinical examinations.

My confidence has become much higher in my ability to treat and evaluate patients. I think that the pro bono clinic has had a very positive effect on me because I was able to practice at school. (STUDENT 2 Journal)

The pro bono clinic is an amazing place to practice being thorough, detail oriented, and considering each system in depth. It allows you to discuss what's important, and maybe what's not so important, when you're in a real-life clinical setting. (FOCUS GROUP 3)

\section{Clinical Reasoning}

Two themes came through the $\mathrm{Cl}$ and student data but at the lowest tier: Clinical Reasoning and Intervention. Interestingly, Cls' ratings and comments depicted both intervention and clinical reasoning as stronger than the students' perceptions. $\mathrm{Cl}$ comments include "thinking on his feet - why he is doing what he is doing," "comes to the correct conclusion most of the time," "better than expected," "can make and defend decisions," and "rationale is on track." In the area of clinical reasoning," 15 of the 30 Cls rated their students at above expected level. Student comments on clinical reasoning were

$\mathrm{My} \mathrm{Cl} \mathrm{commends} \mathrm{me} \mathrm{on} \mathrm{my} \mathrm{ability} \mathrm{to} \mathrm{progress} \mathrm{and} \mathrm{regress} \mathrm{patient} \mathrm{plans} \mathrm{of} \mathrm{care,} \mathrm{which} \mathrm{I} \mathrm{can} \mathrm{attribute} \mathrm{to} \mathrm{my} \mathrm{time} \mathrm{in} \mathrm{the}$ pro bono clinic. (STUDENT 27 Journal) 
I had to discharge a patient and discuss with them how their goals have progressed and that I believe, in my clinical judgement, that they no longer need therapy. I could do this more easily because I have had to discharge a patient in the pro bono clinic. (STUDENT 9 Journal)

\section{Intervention}

Cl comments specific to intervention included, "creative with their ex programs," "knows what do to," "good manual skills," and "above expectations, but not significantly." In the area of competency in interventions," 14 of the 30 Cls rated their students above expected level. Student comments around intervention included

The pro bono clinic has also taught me that I should not just blindly follow a patient's exercise program without actively evaluating them and seeing how they are currently doing and if they need to change their program. I was able to do that this week without my Cl's help because I already knew the importance of being a critical thinker. (STUDENT 9 Journal)

You have to adjust your program to fit the needs of the patient by scaling up or scaling down the exercise. I feel this has happened multiple times in the pro bono clinic where you expected too much of a patient or the exercise was to easy. (STUDENT 17 Journal)

\section{Overarching Theme: Increased Level of Comfort and Preparedness}

The data analysis yielded an overarching theme expressed by both the Cls and students around student increased comfort in their role as a student physical therapist and preparedness for their first full-time clinical experience. The following quotes from a $\mathrm{Cl}$ and a student capture the sentiments of data from both Cls and students.

I think the pro bono clinic is a huge advantage and sets students from this program apart from other schools. The student is much more prepared, I am not wasting my time on the basics. (Cl)

I had several people ask "Are you sure this is your first clinical?" just because of how confident I was and how comfortable with the caseload... I think it's because of the clinic. (FOCUS GROUP 3)

\section{DISCUSSION AND CONCLUSIONS}

A total of 29 student/Cl pairs participated in the investigation, representing a variety of practice settings, including outpatient, acute care/hospital, inpatient rehabilitation, an international site in a developed country, and an international site in a developing country. The most significant difference between the previous study and this one is the consideration of the $\mathrm{Cl}$ ratings and comments. ${ }^{15}$ Inclusion of $\mathrm{Cl}$ perspectives helped to corroborate student perspectives. In this study, $\mathrm{Cl}$ ratings and comments strongly supported the students' perceptions that the students were strong in the overall area of communication with both clients and with Cls. This finding is consistent with the literature. McGehee et al also found that students participating in a pro bono clinic were better at making a connection with the patient than those students that did not participate. ${ }^{10}$ Stickler et al concurred that client interaction experiences afforded by the pro bono clinic increased student comfort with interpersonal communication. ${ }^{12}$

Jette et al identified the development of "professional demeanor" as an essential skill for clinical education. According to Jette et al, professional demeanor includes the ability to take initiative and to accept feedback without being defensive. ${ }^{2}$ In this study, both $\mathrm{Cls}$ and students ranked communication with $\mathrm{Cls}$ high with comments specific to receiving feedback well. The students attributed their lack of defensiveness to their experiences interacting with licensed supervisors and senior student mentors in the pro bono clinic. This was also a strength in the work by Porretta et al. ${ }^{15}$

The Cls noted higher than expected performance in cultural competence and students also identified cultural competence as a strength. The Chester Community Clinic serves uninsured and underinsured members of the community. Students had exposure to clients of varying ethnicities, socioeconomic status, health literacy levels, and religions. Navigating the complexities of language barriers, limited resources, and health literacy is not new to them, and students are able to carryover prior learning in these areas. Improvement in cultural competency with participation in a pro bono clinic is supported in the works of Hoppes et al, Giles et al, Godoshian et al, Geelhoed et al, and Passmore et al. 13,19-21,24 The pro bono setting invites student to broaden their practice, incorporate determinants of health, and begin to see the patient holistically. 
The student emergent themes from this study were very similar to that of the previous work with just a few alterations. ${ }^{15} \mathrm{~A}$ student theme labeled professional communication in the previous study now emerged as interprofessional communication. This likely captured the impact of the growth in interprofessional services within the pro bono clinic since the last study. The students continued to mention Grand Rounds as assisting in their comfort with professional communication; but this time, they are articulating a better understanding of what other health professions do, comfort with interprofessional communication, and treating clients collaboratively. ${ }^{25}$ In the past three years, the pro bono clinic has grown with the added services from occupational therapy and graduate clinical psychology students. The literature corroborates that authentic experience working within a therapy team may promote future interprofessional collaboration, and often these experiences promote opportunity for interprofessional problem solving. ${ }^{16,26}$ Lie et al suggest student experience in an interprofessional pro bono clinic promotes different medical professionals learning "with, from, and about each other" while fostering client advocacy and social responsibility. ${ }^{27}$ The DPT students are now noting unfamiliarity with working with PTA students. This is something for future pro bono growth and consideration.

In the previous study, ${ }^{15}$ students were not expressing as much confidence in clinic examination skills and had expressed regret that they had not sought out an evaluation opportunity in the pro bono clinic. In response to this finding, the student board leadership initiated a clinic policy and tracking system so that now all students are required to perform an evaluation in the pro bono clinic before their first full-time clinical experience. The benefit of this change appears in this study in that students are now identifying an increased confidence in performing evaluations because of their experience in the pro bono clinic. The Cls noted that basic examination skills were better than anticipated as well.

The pro bono clinic experience provided an opportunity for students to develop many clinical and professional traits in a contextbased setting. This early clinical experience promotes student success in several areas as evidenced by the overarching theme of increased comfort, confidence, and preparedness. The findings of this study support the program's determination of student readiness for participation in full-time clinical education. Jette et al described components of entry level skills, including basic knowledge/competence, documentation, self-directed learning, and interpersonal communication. ${ }^{2}$ Students and Cls report better than expected characteristics in many of these areas. Nakamura et al reports student-run clinic experience during the didactic education helps to build student self-confidence, self-reflection skills, and professionalism. ${ }^{28}$ Lie et al. suggest that perceived student self-confidence promotes a climate of collaborative communication, and an appreciation of learning from others. ${ }^{27}$ These affective skills are difficult to teach in a traditional classroom setting. The authentic environment of the pro bono clinic fosters the development of these skills.

\section{Limitations}

This research is limited to this particular pro bono clinic model, at this particular time, and this particular place as is characteristic of qualitative research. It is hoped that the description is rich enough that readers can identify relevance and application to their work. The students were asked to keep journals only until midterm and the Cls were interviewed at midterm. This was done differently than the previous study in hopes of more accurately capturing the strengths specific to the pro bono clinic experience rather than the continued full-time clinic learning experience. The student focus groups; however, were conducted two months after the conclusion of the full-time clinical experience. This timing was not optimal but was done for convenience of gathering students on campus. The research was conducted by two DCEs, two faculty members overseeing community engagement and pro bono activities, and two DPT students who were of the cohort studied. While the researchers challenged one another to bracket their biases and assumptions as they conducted the research, it is quite possible that biases were present. On the other hand, the variety of perspectives facilitated rich dialogue and ultimately a more balanced mining of the data. Finally, this study is limited in that it considers student perceptions and $\mathrm{Cl}$ perceptions and rankings of student who have had significant pro bono clinic experiences.

\section{Recommendations for Future Research}

Future research might look at a comparison group of student CPI ratings who have not had 60-70 hours of pro bono clinic experience prior to their first full-time clinic experience.

\section{Conclusions}

In conclusion, this research demonstrates that both students and Cls agree that participation in a student-run pro bono clinic helps to facilitate student comfort and readiness for a first full-time clinical education experience, particularly in the areas of client interaction, $\mathrm{Cl}$ interaction, professional communication, cultural competency, examination, clinical reasoning, and interventions. 


\section{REFERENCES}

1. Commission on Accreditation in Physical Therapy Education. Standards and required elements for accreditation of physical therapy education programs. (Revised 12/7/17). Available at http://www.capteonline.org/uploadedFiles/CAPTEorg/About_CAPTE/Resources/Accreditation_Handbook/CAPTE_PTS tandardsEvidence.pdf Accessed December 30, 2019.

2. Jette DU, Bertoni A, Coots R, Johnson H, McLaughlin C, Weisbach C. Clinical instructors' perceptions of behaviors that comprise entry-level clinical performance in physical therapy students: a qualitative study. Physical Therapy. 2007;87(7):833-843. [PMID 17601998]

3. Timmerberg JF, Dole R, Silberman N, Goffer SL, Mathur D, Miller A, et al. Physical therapist student readiness for entrance into the first full-time clinical experience: a Delphi study. Physical Therapy. 2019;99(2):131-146. [PMID 30561680]

4. Wainwright SF, Shepard KF, Harman LB, Stephens J. Novice and experienced physical therapist clinicians: a comparison of how reflection is used to inform the clinical decision-making process. Phys Ther. 2010;90(1):75-88. [PMID 19926680]

5. Miller AH, Tomlinson S, Tomlinson JD, Readinger J. Addition of a Patient Examination Module to Address Student Preparedness for the First Full-Time Clinical Experience. Journal of Physical Therapy Education. 2017;31(2):30-43. [PMID not found]

6. Judd B, Fethney J, Alison J, Waters D, Gordon C. Performance in simulation Is associated with clinical practice performance in physical therapist students. Journal of Physical Therapy Education. 2018;32(1):94-99. [PMID not found]

7. Mai JA, Thiele A, O'Dell B, Kruse B, Vaassen M, Priest A. Utilization of an integrated clinical experience in a physical therapist education program. Journal of Physical Therapy Education. 2013;27(2):25-32. [PMID not found]

8. Wilson AM. Integrated clinical experiences in a campus onsite clinic: a self-contained model of physical therapy clinical education. Internet Journal of Allied Health Sciences and Practice. 2014;12(3). Available at https://nsuworks.nova.edu/ijahsp/vol12/iss3/8/ Accessed December 30, 2019. [PMID not found]

9. Nowakowski K, Kaufman R, Pelletier D. A Clinical Service-Learning Program Promotes Mastery of Essential Competencies in Geriatric Physical Therapy. Journal of Physical Therapy Education. 2014; 28 (2):46-53. [PMID not found]

10. McGehee WF, Dunleavy K, Blue AV, Stetten NE, Black EW. Physical therapist students' perceptions: learning from a community-based, client-focused, interprofessional learning experience. Journal of Physical Therapy Education. 2018;32(1):70-76. [PMID not found]

11. Danzl M, Ulanowski E, Carta T, Bridges Y, Conway D, Vessels L. Implementation and experiences of participating in a neurologic service-learning clinic in a physical therapist entry-level program: an educational case report. Journal of Physical Therapy Education. 2019;33(4):298-306. [PMID not found]

12. Stickler L, Grapczynski C, Ritch J. Student perceptions of outcomes from participation in physical therapy pro bono clinics: a qualitative study. Journal of Allied Health. 2013;42(1):46-55. [PMID 23471285]

13. Passmore A, Persic C, Countryman D, Rankine L, Henderson M, Hu, T, et al. Student and preceptor experiences at an inter-professional student-run clinic: a physical therapy perspective. Physiotherapy Canada. 2016;68(4):391-397. [PMID 27904239] 
14. George L, Bemenderfer S, Cappel M, Goncalves K, Hornstein M, Savage C, et al. A model for providing free patient care and integrating student learning and professional development in an interprofessional student-led clinic. Journal of Physical Therapy Education. 2017;31(2):54-66. [PMID not found]

15. Porretta D, Black JD, Palombaro K, Erdman E. Influence that service in a pro bono clinic has on a first fulltime physical therapy clinical education experience. Internet Journal of Allied Health Sciences and Practice. 2017;15(1). Available at https://nsuworks.nova.edu/ijahsp/vol15/iss1/11/ Accessed December 30, 2019. [PMID not found]

16. Doucet BM, Seale J. The free post-stroke clinic: a successful teaching and learning model. Journal of Allied Health. 2012;41(4):162-169. [PMID 23224282]

17. Nordon-Craft A, Schwarz B, Kowalewski V, Hartos J, Severance JJ, Bugnariu N, (2017). Service-learning enhances physical therapy students' ability to examine fall risk in older adults. Journal of Allied Health. 2017;46(3), E51-E58. [PMID 28889172]

18. Stickler K, Sabus C, Gustafson H, Kueser M, Lavavesjkul B, Denney L. Pro-bono service through student-run clinics: how does physical therapy measure up? Journal of Allied Health. 2016;45(3):207-211. [PMID 27585617]

19. Godoshian M, Yorke A. Does participation in physical therapy student-run free clinics realte to altruism, social responsibility, and cultural competency post-graduation? A pilot study. Journal of Student-Run Clinics. 2019; 5:1. Available at https://studentrunfreeclinics.org/journalsrc.org/index.php/jsrc/article/view/88/59 Access January 2, 2020. [PMID not found]

20. Geelhoed MA, Callaway SM, Cruz JM, Subramanian SK. Attitudes of physical therapy students towards the population currently experiencing homelessness: a pilot study. Journal of Allied Health. 2019;48(3):220-225. [PMID 31487362]

21. Gilles J, Bishop M, McGehee W, Lulofs-MacPherson K, Dunleavy K. Impact on clinical performance of required participation in a student-run pro bono clinic. Journal of Physical Therapy Education. 2019;33(3):209-214. [PMID 31487362]

22. Palombaro KM, Dole RD, Lattanzi JB. A case report of a student-led pro bono clinic: a proposed model for meeting student and community needs in a sustainable manner. Phys Ther. 2011;91(11):1-9. [PMID 21868614]

23. American Physical Therapy Association. Physical Therapist Clinical Performance Instrument for Students. Available at http://cpi2.amsapps.com/docs/PT_final_revision_11-30-2010.pdf Accessed October 27, 2017.

24. Hoppes $S$, Bender D, DeGrace B. Service learning is a perfect fit for occupational and physical therapy education. Journal of Allied Health. 2005;34(1):47-50. [PMID 15839606]

25. Black JD, Bauer KN, Spano GE, Voelkel SA, Palombaro KM. Grand rounds: a method for improving student learning and client care continuity in a student-run physical therapy pro bono clinic. Journal of the Scholarship of Teaching and Learning. 2017;17(3): 68-88. [PMID not found]

26. Wise HH, Frost JS, Resnik C, Davis BP, Iglarsh ZA. Interprofessional education: an exploration in physical therapist education. Journal of Physical Therapy Education. 2015;29(2):72-83. [PMID not found]

27. Lie DA, Forest CP, Walsh A, Banzali Y, Lohenry K. What and how do students learn in an interprofessional studentrun clinic? An educational framework for team-based care. Medical Education Online. 2016;21:1. [PMID 27499364]

28. Nakamura M, Altshuler D, Binienda J. Clinical skills development in student-run free clinic volunteers: a multi-trait, multi-measure study. BMC Medical Education. 2014;14:250. Available at https://doi.org/10.1186/s12909-014-0250-9 Accessed January 2, 2020. [PMID 25495286] 


\section{APPENDIX A. Student Journal Instructions}

Please reflect upon and document anytime when you called upon your experience in the pro bono clinic to help your performance in the full-time clinical experience. Examples include:

$\sim$ recognition of diagnoses / impairments

program progression

$\sim$ confidence which you can attribute to experience in the pro bono clinic

$\sim$ interpersonal communication enhanced by pro bono experience

$\sim$ cultural encounters that were improved because of pro bono experience

interaction / communication with clinical instructor that may have been enhanced by interaction with pro bono clinic supervisors

$\sim$ documentation skills

$\sim$ anything else

Please complete this reflection at least once / week.

\section{APPENDIX B. Focus Group Guide}

Focus Group Questions

1. Tell us more about your interactions with your $\mathrm{Cl}$.

Was the relationship comfortable? Did you initiate/pose questions or were you responding to your Cl's questions? Tell us about when you first took the lead in a therapy session.

Accepting feedback?

2. We recognize that you were in different settings, some more like the pro bono clinic than others. Can you reflect on the impact of the pro bono clinic on your clinical experience?

(If only one side of the argument is brought up) What did or did not the pro bono clinic help with/prepare for?

3. In what ways were you not prepared for your first full-time clinic experience?

4. Can you speak to preparedness around direct clinical care that the pro bono clinic provided?

5. Can you tell us about interprofessional interactions?

6. Can you tell us about any cultural encounters?

7. Is there anything else you would like to add?

\section{APPENDIX C. QUESTIONS FOR THE CLINICAL INSTRUCTOR:}

For Consenting Cls participating in the study - consent attained: Verbal: Cl info:

Written:

\# of years in practice

\# years as a clinical instructor 
\# of students supervised in their career

Have you taken a course in being a $\mathrm{Cl}$ ?

On a scale of $1-5$, please rate the student's performance during the first few weeks, as compared to your DPT student expectations for a first full time clinical experience,

$1=$ below expected level

$3=$ at expected level for education

$5=$ performance exceeds expectations for this level of education

Please describe the student's performance in the first few weeks, as compared to DPT student expectations for a first full time clinical experience, in regards to:

\begin{tabular}{|l|l|l|l|l|l|l|}
\hline CPI Skill Area & 1 & 2 & 3 & 4 & 5 & Comments: \\
\hline 1. Communication/interaction with patient & & & & & & \\
\hline 2. Ability to accept and utilize feedback from you & & & & & & \\
\hline 3. Professional Communication & & & & & & \\
\hline 4. Documentation & & & & & & \\
\hline 5. Competency in Examination & & & & & & \\
\hline 6. Competency in Interventions & & & & & & \\
\hline 7. Competency in Clinical Reasoning & & & & & & \\
\hline 8. Competency in Cultural Encounters & & & & & & \\
\hline
\end{tabular}

Interviewer's Initials:

Practice Setting: 